\title{
1. Introduction: women entrepreneurs and growth
}

\author{
Candida G. Brush, Anne de Bruin, \\ Elizabeth J. Gatewood and Colette Henry
}

Women-owned businesses are one of the fastest growing entrepreneurial populations in the world. They make significant contributions to innovation, employment and wealth creation in all economies (Brush et al., 2006). Statistics from the Global Entrepreneurship Monitor (GEM) indicate that women entrepreneurs create and run businesses across all of the broad industrial sectors of extraction, transformation, business services and consumeroriented products. Women in developed economies are more likely to start businesses out of opportunity motivation while those in less developed economies are motivated by necessity. Latin America and Asia have higher rates of entrepreneurial activity for women than Europe and the US. However, women entrepreneurs make significant contributions to economies in terms of jobs, innovations and gross national product (Allen et al., 2007).

Despite the growing importance of women entrepreneurs, they are understudied and the paucity of research on the phenomenon of women's entrepreneurship is well documented (Baker et al., 1997; de Bruin et al., 2006, 2007). Recent literature reviews suggest that studies about women entrepreneurs comprise less than 10 per cent of all research in the field. The result is that we know comparatively little about women entrepreneurs even though they contribute positively to gross national product (GNP), jobs, innovations and societal welfare globally. For the past 10 years, the Diana Project has worked to resolve this disparity.

\section{THE DIANA PROJECT}

Early research on women's entrepreneurship focused on factors influencing the start-up of ventures (Gatewood et al., 2003). Notably absent was an understanding of factors affecting growth. In 1999, Candida Brush, Nancy Carter, Elizabeth Gatewood, Patricia Greene and Myra Hart 
launched the Diana Project to study the phenomenon of women's entrepreneurship in the United States. Historically, women-led ventures were smaller than those led by men, whether measured by size of revenues generated or the number of people employed. The overarching question was, 'Why do women-owned businesses remain smaller than those of their male counterparts?' A multi-method research effort was undertaken to examine supply of and demand for growth capital relative to women entrepreneurs. United States research showed that women entrepreneurs seldom acquired sufficient funds to grow their businesses aggressively and to reach their full potential. This raised a new question, 'Do women face unique challenges in acquiring growth capital?'

While the collective research documents the demand by women entrepreneurs for equity capital, there was and still is a mismatch between the women, their ventures and sources of growth funding (Brush, et al., 2001b, 2004b). The Diana Project findings prompted great interest amongst the media, policy-makers, practitioners and educators wanting to learn more about ways to increase women entrepreneurs' receipt of growth capital by providing a better infrastructure of programmes and curricula for women who wished to grow larger businesses (see, for example: Hart, 2003; Henry, 2002; Hoover, 2002; Montandon, 2002). All these audiences shared the objective of facilitating the growth of new businesses that could produce innovation and wealth for the benefit of individual entrepreneurs, their families and ultimately their communities.

Simultaneous to the Diana Project research, interest in women entrepreneurs and growth of their ventures was rising in most countries around the world. To capture and leverage that interest, the Diana Project team, in partnership with ESBRI (Entrepreneurship and Small Business Research Institute, Sweden), convened an international gathering of scholars in 2003 to develop a shared research agenda. The goal was to exchange ideas and learn from each other about the current state of research on creation and support for new women-led businesses, and particularly, support and development of growth-oriented businesses. The purpose of creating the Diana International collaborative was twofold:

- To provide a platform from which to develop, conduct and share a global research agenda.

- To create an international community of scholars dedicated to answering the questions about women entrepreneurs and growthoriented businesses.

The product of the first Diana International Conference in 2003 was a report discussing the importance of growth-oriented women-led 
businesses and summarizing the state of knowledge about these businesses in the initial countries involved. This report was released in spring of 2005 and provided a summary of the presentations about the state of women's entrepreneurship by country. For the second conference in 2004, participants presented working papers. Following the event, papers were peer reviewed, revised and finally submitted for consideration for an edited volume entitled Growth-Oriented Women Entrepreneurs and their Businesses (Brush et al., 2006). The book is the product of the second Diana International Conference which represents the hard work and dedication of an expanded community of scholars passionate about understanding the growth of women's entrepreneurship.

Since 2004, research conferences were held in Stockholm $(2005,2006)$, Madrid (2007), and Belfast (2008). The Belfast conference was attended by more than 100 international scholars. Several special issues of journals have published refereed work specifically on the topic of women's entrepreneurship, notably: Entrepreneurship Theory and Practice (2 volumes), Venture Capital Journal, Entrepreneurship and Regional Development, the Journal of Enterprising Culture, International Journal of Entrepreneurial Behaviour and Research and International Small Business Journal. In addition, a new journal, the International Journal of Gender and Entrepreneurship was launched in 2008 and has published its first volume. In 2007 the founders of the Diana Project were awarded the prestigious Global Award for Entrepreneurship Research sponsored by the Swedish Entrepreneurship Forum, the Swedish Agency for Economic and Regional Growth and the Research Institute of Industrial Economics. Collectively, these efforts demonstrate significant progress in building a global research agenda and a growing community of scholars that can address the deficit in our knowledge of women entrepreneurs.

\section{A FRAMEWORK FOR GROWTH}

Growth-Oriented Women Entrepreneurs and their Businesses (Brush et al., 2006) introduced a framework to examine the factors influencing the growth of individual women-led businesses. This framework discussed four main constructs: the individual, venture concept, firm resources and institutional financial resources. Additionally, the framework showed that the potential for growth was influenced by both the business sector and the country context.

In this second volume, for continuity and consistency, we utilize these same framework elements but modify its portrayal to highlight that the individual is nested within the family. Figure 1.1 thus shows the individual 


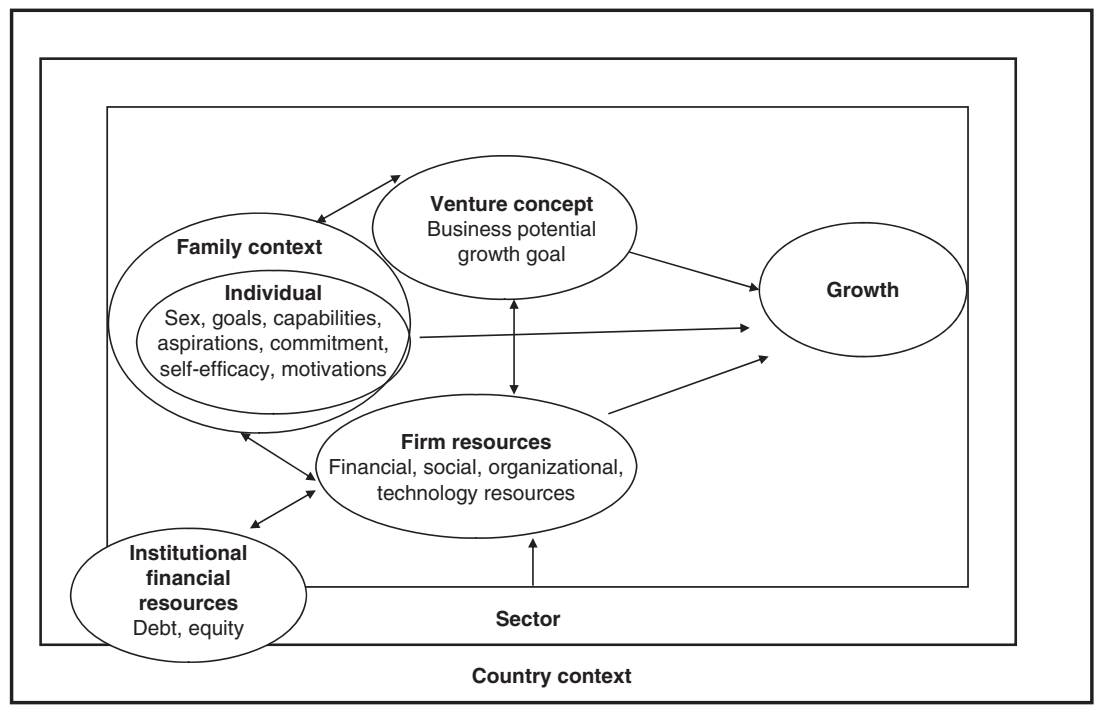

Source: Adapted from Brush et al. (2004a).

Figure 1.1 Research framework for women and growth businesses

enveloped within an outer circle of the family. Our interpretation of the framework also differs since we place greater emphasis on the need for contextualizing women's entrepreneurship at various levels including family and other institutional contexts.

The foundation for any new venture is the individual and the initial package of capabilities and resources that the entrepreneur and her team bring to the table. Not only does the entrepreneur's level of formal education and on-the-job experience and training have a positive relation to success, but so does women's self-assessment of having adequate skills and knowledge (Langowitz and Minniti, 2007). Male and female entrepreneurs also tend to differ in their aspirations and strategic choices, with some women intentionally preferring to keep their businesses smaller (Cliff, 1998; Orser and Hogarth-Scott, 2002). Other individual-level factors such as personal traits and the motivation for starting the business can vary widely (Buttner and Moore, 1997). While the entrepreneur's human capital, characteristics, motivations and aspirations form the base for the venture, entrepreneurs are not atomistic actors. They are embedded within their household and family context which usually has a larger impact on women than men in the entrepreneurial process (Brush et al., 2009).

The venture concept is what the business does or the product or service it 
provides (Bhide, 2000). It starts from an idea, innovation or a problem and is transformed into a concept which forms the basis of the organization. Breakthrough ideas, a solution to an important problem, or the creation of a product with low substitutes which will cater to a large market instead of a low-value niche, will spawn organizations with a high growth potential. Such business concepts are also likely to have a higher probability of attracting external funding for growth (Timmons and Bygrave, 1997).

Firm resources are used to convert the concept into reality and take the goods and services to market (Penrose, 1954). Resources fall into several categories: social, financial, organizational, physical and technical (Brush et al., 2001a). Social capital is a form of non-economic knowledge and emerges from norms, relationships and social structures in an individual's life (Coleman, 1988). This includes the network of contacts and reputation, as well as the skills and expertise that help entrepreneurs and their teams acquire the resources of the emerging organization (Aldrich, 1999). Other resources include organizational resources which are those relationships, structures, routines and information of the new venture (Dollinger, 1995). Physical resources include tangible and intangible assets needed for the operations of the business (Dollinger, 1995). These also may include technology and equipment as well as materials and other physical assets of the business. Financial resources are the cash and money assets of the business (Bygrave, 1992). Often personal savings of the entrepreneur and team are the first financial resources available to the firm.

The business sector or industry in which the venture operates also has implications for growth (Carter et al., 1997). Women are concentrated in sectors such as retailing, personal care services, catering and restaurants, which are characterized by ease of entry and low start-up financial capital. These sectors are intensely competitive and overcrowded and this limits growth potential (Brush et al., 2004a; Marlow et al., 2008).

Institutional financial resources comprise external funding sources outside the venture. The availability of and access to external financial capital from private sector financial institutions and equity providers, including venture capitalists and angels, is usually a prerequisite for business growth. There continues to be differences in external funding patterns between male and female-owned businesses (Brush et al., 2001b; Greene et al., 1999; Haines et al., 1999). In contrast to the earlier discussion, we seek here to explore some explanations for these differences, by highlighting how in Figure 1.1 this element intersects both the sector and the country context. With regard to the former, studies suggest that structural factors including sector-related factors can account for sex differences in external funding (for example, Haines et al., 1999). Other studies, however, suggest there is an unexplained gender residual (for example, Verheul and 
Thurik, 2000). Consideration of other institutional factors, as indicated by the intersection with country context in Figure 1.1, may thus provide fertile ground for investigation. For us it also serves to emphasize that country contexts could explain how the role of women is socially constructed. Gender stereotyping also prevails and could impact powerfully in the entrepreneurship arena where in many countries entrepreneurs are perceived to have predominantly masculine characteristics (Gupta et al., 2009). As Carter et al. (2007: 440) point out in relation to external funding of ventures by banks, 'gender remains an important but often hidden variable'.

Our framework provides the basis for dividing the chapters into two broad sections. Part I comprises chapters that highlight how contextual factors, and especially the social and family embeddedness of entrepreneurs, have a differential impact on men and women. Chapters in Part II examine strategies, constraints and enablers of growth and performance, considering a wide variety of topics, including self-efficacy, mentors, networks, socio-political and technology sector factors.

\section{CONTEXTUAL FACTORS}

This section opens with a chapter that seeks in depth understanding of differences in gender entrepreneurship rates and job creation and the reasons for these differences. Using European Union (EU) survey data on wages and self-employment, Marc Cowling (Chapter 2) considers several questions related to the likelihood of women becoming entrepreneurs and creating jobs as compared to men, across different countries in Europe. He finds that gender differences in both cases were large, with men being significantly more likely to choose self-employment over waged employment and to be job creating self-employed. However, econometric investigation shows that the basic reason for the observed difference in self-employment rates between men and women were easily explained by differences in the nature of jobs they enter and the sectors they work in. Further investigation of the data shows that childcare and eldercare responsibilities actually increase the probability that women will choose self-employment and create jobs in self-employment. The chapter concludes with implications for policy.

Gry Alsos, Ragnhild Steen Jensen and Elisabet Ljunggren (Chapter 3 ) discuss the possible cultural, historical, social and economic reasons for what they termed 'the women entrepreneurship paradox'. Despite Norway pioneering gender equality, providing childcare and other social services, and a high rate of women in the labour force, the share of women 
entrepreneurs remains relatively low. According to the authors, the gendered construction of entrepreneurship is rooted in historical paths and reinforced through contemporary practices, such as the gendered division of labour, the tendency for women to work part-time and family-friendly policies strengthening the connotation of family and domestic tasks as female. These practices influence the likelihood of women becoming entrepreneurs and business owners. Interestingly, the authors argue that entrepreneurship is an important part of the capitalistic system, and capitalism is fundamentally gendered.

Annu Kotiranta, Anne Kovalainen and Petri Rouvinen (Chapter 4) identify the same 'paradox' in Finland. Despite labour force participation, political activity and gender-specific legislation, women's participation in the highest level of management and decision-making in Finland is very low. They contend that encouraging greater women's participation at this level is important for economic and competitive reasons. The authors examine the positive and significant correlation between female leadership and company profitability to posit possible reasons for this correlation. Their findings are consistent with the explanation that women go through a tougher 'screening' process and, therefore, the average leadership abilities of women in top management may be better than those of their male counterparts. They offer a possible explanation: that female leadership may be tied to the culture of organizations where advancement and appointments in these organizations are based on competence and merits rather than traditions and established conventions. Although not able to prove causality for their results, they suggest that a company may gain competitive advantage by identifying and eliminating the obstacles to women's advancement to top management.

The chapter by Lorna Treanor and Colette Henry (Chapter 5) compares influences on women's entrepreneurship in the Republic of Ireland and the Czech Republic. The study compares and contrasts the experiences, motivations, characteristics and influences on Irish and Czech women entrepreneurs in relation to business start-up and growth. The data were drawn from one sample in each country, of participants in a European Community Initiative under the EQUAL programme - the 'Supporting Unusual Entry Entrepreneurs' project, which sought to enhance social inclusion through entrepreneurship by providing supports to aspiring entrepreneurs in under-represented groups, in this case, women. Grounded in the literature on gender and entrepreneurship, the authors employ a highly qualitative methodology to explore how typical or atypical these women entrepreneurs are in comparison to the currently held female entrepreneurial 'norm' depicted in the literature. Key similarities were identified with respect to the women's business and personal profiles and 
the sectors in which they operated (mainly services, particularly retail). Major differences related to business growth and size. Their findings lend support to recent literature from institutional theory and suggest a number of interesting future research directions.

Friederike Welter and David Smallbone (Chapter 6) focus on the transition economies of Belarus, Moldova, Ukraine and Uzbekistan. They apply an institutional theory perspective to women's entrepreneurship in these countries and explore different levels of embeddedness and the impact of change. During Soviet times, women experienced different institutional 'realities', and these had significant implications for their opportunities to engage in entrepreneurial activities once transition started. The chapter conceptualizes the different layers of institutional embeddedness with respect to women's entrepreneurship, and links this to Soviet and post-Soviet experiences. Despite the contradictory attitudes of postSoviet societies towards working women, the transition has contributed to the emergence of women entrepreneurs in the former Soviet Republics. Women's entrepreneurship plays an important role in modernizing these societies and in contributing to changing public attitudes towards women. The evidence presented by the authors demonstrates the contribution of women entrepreneurs to social change and to alleviating some of the negative effects of transformation through offering job possibilities for other women (as well as men) and providing positive role models.

Home-based producers in Jordan are the focus of the study by Haya Al-Dajani and Sara Carter (Chapter 7). The chapter identifies the processes through which women entrepreneurs empower home-based women producers and considers best practices for women's empowerment. The authors argue that an increase in popularity of home-based production among women in the Middle East will lead to increased economic significance beyond the informal work sector. Consequently, the direct effects on women's empowerment need to be addressed by researchers and policy-makers, especially in light of the gender segregated market phenomenon that has recently materialized within the region. The experiences discussed in this chapter illustrate the ways in which women-owned small and medium-sized enterprises (SMEs) contribute to the empowerment of home-based producers. By providing the home-based producers with market access, higher financial rewards and benefits than those provided in other sectors, as well as role models, independence and mobility beyond the local community, women entrepreneurs display a stronger understanding of home-based production than non-profit organizations, aid agencies and local policy-makers in the Middle East. The results from this particular study suggest that occupational gender segregation may, inadvertently, offer a potential route to women's empowerment. 
The final chapter in this section highlights that both the family embeddedness of women and the particular institutional country context have an influence on the pathways of women entrepreneurs. Vartuhí Tonoyan, Michelle Budig and Robert Strohmeyer (Chapter 8) examine the impact of family structure (motherhood and partner's occupational status) and family policies (such as publicly funded childcare, maternity leave length) on entry into professional and non-professional entrepreneurship in the US and Europe. They test a series of hypotheses across 23 countries using data from the European Labor Force Survey and the National Longitudinal Survey of Youth for American data. Results show significant heterogeneity in women's self-employment. In contrast to motherhood, which is only a predictor for women's entry into non-professional self-employment, spousal self-employment is strongly positively associated with both professional and non-professional self-employment. Their findings suggest that institutional variations between welfare states are responsible for cross-country variations of the occupational status of women's self-employment. This study has many implications for policy and future research.

\section{GROWTH STRATEGIES AND ENABLERS}

Prompted by the need for new approaches to explain why women-led businesses 'underperform' relative to businesses led by men, Jennifer Jennings, Karen Hughes and Devereaux Jennings (Chapter 9) adopt a family embeddedness perspective by examining claims that there are significant differences in how female and male entrepreneurs manage the work-family interface (WFI). They build on the theoretical work of Jennings and McDougald (2007) and utilize survey data from 163 businesses in Alberta, Canada, to provide one of the first empirical examinations of the WFI strategies used by male and female business owners. Their analysis focuses on growth-constraining and growth-facilitating WFI strategies at both the individual and couple level. Contrary to expectations, they observe very few gender differences overall. Testing for gender differences within the three distinct industry sectors in which their sample firms operated manufacturing; retail, wholesale and general services; and professional services - revealed that while there was little gender difference in the manufacturing sector, far more gender differences were evident in the other two sectors, and the pattern of differences was not identical. These findings highlight the importance of considering context more explicitly within women's entrepreneurship theory and research.

The chapter by Eleanor Shaw, Sara Carter and Wing Lam (Chapter 
10) recognizes that the financing of entrepreneurial ventures is a complex process influenced by a range of economic, personal and societal factors. Using data from 30 matched pairs of male- and female-owned businesses in Scotland, they adopt an entrepreneurial capital perspective to explore the interplay between gender, finance and business ownership. Findings show the impact of non-financial capital on women entrepreneurs' possession of and access to finance. Their discussion contributes to the discourse on the gender, business ownership and finance nexus in a number of ways. First, the theoretical and methodological framework developed reveals the subtle, complex relationship between gender and entrepreneurial capital. Secondly, the chapter provides women business owners with deeper insights into the sources of some of the challenges they could face when financing their ventures, and may help women understand their own role in enacting these challenges. Thirdly, the insight into the interrelationship and implications between social structure and entrepreneurship could usefully be considered when developing policy directed to encourage more women into business ownership.

Frances Hill, Claire Leitch and Richard Harrison (Chapter 11) examine a small sample of high-technology businesses in Northern Ireland, focusing on a number of issues related to business growth. The matched samples of men and women business owners/managers were selected on the basis of firm characteristics (high-technology, business to business, less than 15 years old) and personal characteristics relating to human and social capital. The authors reported more similarities than differences among the women and men in the sample, confirming past findings. However, the authors found a few noteworthy differences. In general men and women had the same growth aspirations but women were less confident about exporting, which could limit future growth. Women and men were active networkers, however, women reported fewer benefits from networking and were less likely to belong to informal networks. One finding, which contradicts past research, is that men had greater reservations about seeking external funding than women. Although women showed a greater propensity to fund growth from external sources, women were unhappy with the amount of funding they received.

Kim Klyver and Siri Terjesen (Chapter 12) use data from entrepreneurs in Denmark to explore gender differences in the composition of social networks at four distinct phases of the new venture process. Consistent with prior research, they find that when compared with male entrepreneurs, female entrepreneurs have significantly lower proportions of males in their social networks. However, females' proportion of males in their networks increases in later venture development stages, suggesting that female entrepreneurs, who are able to persist in the new venture process, 
end up developing networks similar to those of their male counterparts. They find that female entrepreneurs report larger networks than their male counterparts, however, there are no gender differences in terms of density or composition with respect to the proportion of business, family or emotional support relations.

Rodney Farr-Wharton and Yvonne Brunetto (Chapter 13) focus on the importance of internal employee networks within the SME sector. They examine data on how 58 female and 64 male entrepreneurs located in Australia search for new business opportunities. In particular, using a learning organization lens, their findings provide reinforcing evidence that a majority of entrepreneurs do not actively seek new business opportunities from their interactions with employees. A networking and social capital lens is also used to provide interesting insights. They find evidence that the quality of social capital is far more important for female entrepreneurs compared with male entrepreneurs in embedding relationship-based management. Female entrepreneurs were more likely to use a relational management approach, which means that they were fostering the development of social capital and reciprocity of positive behaviour such as information sharing, resources and respect. Such behaviour becomes evident in the socializing processes in meetings and conversations that some of the female entrepreneurs promoted. These appeared to generate ideal conditions for learning about and acknowledging new business opportunities from internal employee networks.

Maura McAdam and Susan Marlow (Chapter 14) explore the incubator environment as a resource for women entrepreneurs using a case study of a woman entrepreneur with a business operating in the Science, Engineering and Technology (SET) sector. Although the number of women SET graduates has increased dramatically in Ireland, evidence exists that they are vertically integrated in lower positions and exit SET careers early. Entrepreneurial careers would appear to be a strategy for SET women to deal with the negative impacts of occupational segregation, however, women remain under-represented as business owners. The authors found that the business incubator model is appropriate for providing infrastructure, business and professional support, networks, and credibility to SET women entrepreneurs. However, the authors also found that the incubator culture remains highly gendered. They call for incubators to have greater recognition and value for women's operating preferences.

The chapter by Barbara Orser and Joanne Leck (Chapter 15) examines the evolution of a 'for women and by women' public health care centre in Canada, to discuss the gendered nature of the venture creation process. Specifically, they seek to understand the ways in which gender is embedded in opportunity recognition, resource acquisition and organizational 
form. Building on entrepreneurship and feminist theory, they present a gender-based typology of new venture organizations and the construct of 'feminist entrepreneur'. Feminist entrepreneurs are defined as change agents who seek to improve women's quality of life and well-being through innovative services, products and processes. The motives of these entrepreneurs are explicitly, although not exclusively, focused on enhancing women's life conditions. Orser and Leck use participant-observation and content analysis to document how gender is enacted in an entrepreneurial health care venture. Their study also provides insights on the 'silencing' of women's entrepreneurship in the sector. Observations call for executive leadership and tools to institutionalize integrated health care. Implications for health care and entrepreneurship research are considered.

While a plethora of studies has been carried out to explain the success of women-owned SMEs in advanced countries, research on entrepreneurship in transition economies is less developed. Jill Kickul, Mark Griffiths, Lisa Gundry and Tatiana Iakovleva (Chapter 16) add new theoretical and empirical insights to factors influencing the success of small firms owned and operated by women in the Russian transition economy. They consider the role of mentoring and self-efficacy on the performance of women-led firms. The sample on which the study is based comprised 555 Russian women entrepreneurs, and the results indicate that mentoring is an important developmental relationship that facilitates self-efficacy and influences the sustainability of firm performance. By understanding how mentors and role models support women in these tenuous environments, we are better able to create the support systems to nurture and support women's entrepreneurial efforts. Implications for women entrepreneurs in emerging and transitioning economies are presented.

The chapter on Slovenian entrepreneurs authored by Karin Širec, Polona Tominc and Miroslav Rebernik (Chapter 17) deals with the perceived differences in growth aspirations among female and male entrepreneurs. As the authors explain, although not all entrepreneurs' expectations materialize, growth aspirations have been shown to be a good predictor of eventual growth, and technology orientation may also play a part. Their findings reveal that current growth potential among entrepreneurs in Slovenia differs according to gender. In addition, a significant positive relationship between the intensity of applied new technologies and growth aspirations among Slovenian SMEs is confirmed. There are particular gender differences in growth aspirations. Males aspire to increase sales revenue, whereas women aspire to grow their company assets. However, neither men nor women aspire to promote employment growth. Increasing our understanding of these aspects of growth can help strengthen the empirical micro-level basis of theories of entrepreneurship and innovation. 


\section{ADVANCING THE GLOBAL RESEARCH AGENDA}

During the decade since the launch of the Diana Project in 1999, women's entrepreneurship research and understanding of factors affecting the growth of women-owned business have advanced significantly. There is also heightened awareness that 'the landscape of women's entrepreneurship is gendered terrain' (Brush et al., 2009: 18). The contributions in this volume aptly demonstrate that a well-focused gender lens is necessary to delve further into explaining the phenomenon of women's entrepreneurship.

Many of the chapters in this volume have heeded the suggestion of de Bruin et al. (2007: 323) that 'a separate theory on women's entrepreneurship may not be required. Rather, existing theoretical concepts should be expanded to incorporate explanations for the distinctiveness of women's entrepreneurship, and current theoretical approaches, which are normally used in trying to explain women's entrepreneurship, should be broadened'. For instance an institutional analysis is used in the chapters by Tonoyan et al. and Welter and Smallbone. The latter chapter also explores variants of the embeddedness notion that institutional theory acknowledges and suggests the concept of mixed embeddedness as a potentially useful overarching conceptual framework for analysing women's entrepreneurship in transition conditions. Other examples, among several, of building on existing theoretical explanations are the chapter by Jennings et al., which builds on the family embeddedness approach in entrepreneurship research, and Orser and Leck, who utilize entrepreneurship and feminist theory to advance the construct of 'feminist entrepreneur'.

Moving forward, we believe it is important to build a holistic community whereby research about women's entrepreneurship not only continues to explore and develop theory but also examines questions and disseminates findings so as to inform policy and practice. In other words, the virtuous cycle of research should feed into policies and practice which should inform teaching and educational approaches. An exciting example is the Women's International Centre for Economic Development (WICED) located in Liverpool, UK. This organization focuses on helping women to start and grow their own businesses, and creating the conditions and infrastructure that will help achieve this. This world-leading concept now taking shape in Liverpool will, both through the physical form and intellectually, provide a beacon by which to raise all our aspirations for women's economic development. By bringing together the elements of research, gendered business incubation and high-quality business support, WICED hopes to achieve the aim of more women's businesses, creating 
more wealth and prosperity. The Diana International Project and all the scholars contributing to this volume are providing research that provides a foundation for expanding the work and vision of WICED.

It is our hope that this second volume contributes to existing knowledge about women's entrepreneurship and growth, raises new questions and inspires more research especially about women in emerging and less developed economies.

\section{REFERENCES}

Aldrich, H. (1999), Organizations Evolving, Thousand Oaks, CA: Sage Publications.

Allen, E., Elam, E., Langowitz, N. and Dean, M. (2007), The GEM Women's Report. Wellesley, MA: Babson College, Center for Women's Leadership.

Baker, T., Aldrich, H. and Liou, N. (1997), 'Invisible entrepreneurs: the neglect of women business owners by mass media and scholarly journals in the USA', Entrepreneurship and Regional Development, 9 (2), 221-38.

Bhide, A. (2000), The Origin and Evolution of New Businesses, New York: Oxford University Press.

Brush, C., Carter, N.M., Gatewood, E.J., Greene, P.G. and Hart, M.M. (2006), 'Introduction: the Diana Project International', in C. Brush, N.M. Carter, E.J. Gatewood, P.G. Greene and M.M. Hart, Growth-Oriented Women Entrepreneurs and their Businesses, Cheltenham, UK and Northampton, MA, USA: Edward Elgar.

Brush, C., Carter, N., Gatewood, E., Greene, P. and Hart. M. (2004a), Clearing the Hurdles: Women Building High-Growth Businesses, Upper Saddle River, NJ: Financial Times Prentice Hall Books.

Brush, C., Carter, N., Gatewood, E., Greene, P. \& Hart, M. (2004b), The Diana Project. Gatekeepers of Venture Growth: The Role and Participation of Women in the Venture Capital Industry, Report 2, Kansas City, MO: Ewing Marion Kauffman Foundation.

Brush, C., Carter, N., Greene, P., Gatewood, E. and Hart, M. (2001b), 'An investigation of women-led firms and venture capital investment', report prepared for the U.S. Small Business Administration Office of Advocacy and the National Women's Business Council.

Brush, C., de Bruin, A. and Welter, F. (2009), 'A gender-aware framework for women's entrepreneurship', International Journal of Gender and Entrepreneurship, 1, 8-24.

Brush, C.G., Greene, P.G. and Hart, M.M. (2001a), 'From initial idea to unique advantage: the entrepreneurial challenge of constructing a resource base', Academy of Management Executive, 15 (1), 64-80.

Buttner, E.H. and Moore, D.P. (1997), 'Women's organizational exodus to entrepreneurship: self-reported motivations and correlates with success', Journal of Small Business Management, 35 (1), 34-46.

Bygrave, W.D. (1992), 'Venture capital returns in the 1980s', in D.L. Sexton and J. Kasarda (eds), The State of the Art of Entrepreneurship, Boston, MA: PWS Kent. 
Carter, N.M., Williams, M. and Reynolds, P.D. (1997), 'Discontinuance among new firms in retail: the influence of initial resources, strategy, and gender', Journal of Business Venturing, 12, 125-45.

Carter, S., Shaw, E., Wilson, F. and Lam, W. (2007), 'Gender, entrepreneurship and bank lending', Entrepreneurship Theory and Practice, 31(3), 427-44.

Cliff, J.E. (1998), 'Does one size fit all? Exploring the relationship between attitudes between growth, gender and business size', Journal of Business Venturing, $13(6), 523-42$.

Coleman, J. (1988), 'Social capital in the creation of human capital', American Journal of Sociology, 94, S95-S120.

De Bruin, A., Brush, C. and Welter, F. (2007), 'Advancing a framework for coherent research on women's entrepreneurship', Entrepreneurship Theory and Practice, 31 (3), 323-39.

De Bruin, A., Brush, C. and Welter, F. (2006), 'Introduction to the special issue: towards building cumulative knowledge on women's entrepreneurship', Entrepreneurship Theory and Practice, 30 (5), 585-94.

Dollinger, M. (1995), Entrepreneurship: Strategies and Resources, Boston, MA: Irwin.

Gatewood, E.G., Carter, N.M., Brush, C.G., Greene, P.G. and Hart, M.M. (2003), Women Entrepreneurs, their Ventures, and the Venture Capital Industry: An Annotated Bibliography, Stockholm: ESBRI.

Greene, P., Brush, C., Hart, M. and Saparito, P. (1999), 'An exploration of the venture capital industry: is gender an issue?', in P.D. Reynolds, W. Bygrave, S. Manigart, C. Mason, G.D. Meyer, H. Sapienza and K.G. Shaver (eds), Frontiers of Entrepreneurship Research, Wellesley, MA: Babson College.

Gupta, V.K., Turban, D.B., Wasti, S.A. and Sikdar, A. (2009), 'The role of gender stereotypes in perceptions of entrepreneurs and intentions to become an entrepreneur', Entrepreneurship Theory and Practice, 33 (2), 397-417.

Haines, G.H., Orser, B.J. and Riding, A.L. (1999), 'Myths and realities: an empirical study of banks and the gender of small business clients', Canadian Journal of Administrative Sciences, 16 (4), 291-307.

Hart, D. (ed.) (2003), The Emergence of Entrepreneurship Policy: Governance Start-ups and Growth in the U.S. Knowledge Economy, Cambridge: Cambridge University Press.

Henry, S. (2002), 'Women Fighting for Venture Capital Study: Study Cites Entrepreneur Networks', Washington Post, 13 February, p. E05.

Hoover, K. (2002), 'Women entrepreneurs push for greater access to venture capital', Washington D. C. Business Journal, 22 February.

Jennings, J.E. and McDougald, M.S. (2007), 'Work-family interface experiences and strategies: consequences for entrepreneurship research and practice', Academy of Management Review, 32, 747-60.

Langowitz, N. and Minniti, M. (2007) 'The entrepreneurial propensity of women', Entrepreneurship Theory and Practice, 31 (3), 341-64.

Marlow, S., Carter, S. and Shaw, E. (2008), 'Constructing female entrepreneurship policy in the UK: is the US a relevant benchmark?', Environment and Planning C: Government and Policy, 26 (2), 335-51.

Montandon, M. (2002), 'The ol' gal money hunt', Fortune Small Business, available at: http://www.fortune.com/indexw.jhtml?channel=artcol.jhtml\&doc_id= 207032 (accessed April 2002).

Orser, B. and Hogarth-Scott, S. (2002), 'Opting for growth: gender dimensions of 
choosing enterprise development', Canadian Journal of Administrative Sciences, 19 (3), 284-300.

Penrose, E. (1954), Theory of Growth of the Firm, New York: John Wiley.

Timmons, J. and Bygrave, W. (1997), 'Venture capital: reflections and projections', in D.L. Sexton and R. Smilor (eds), Entrepreneurship 2000, Chicago, IL: Upstart, pp. 29-46.

Verheul, I. and Thurik, R. (2000), Start-up Capital: Differences between Male and Female Entrepreneurs. Does Gender Matter? EIM Research Report 9910/E, Rotterdam: Erasmus University. 